\title{
THE IMPORTANCE OF INFORMAL LEARNING IN THE COMMUNITY FOR OLDER MEN: MEN'S SHEDS AS A CASE STUDY Interview with Prof. Barry Golding
}

Life is a journey and while walking on this path, many people, through personal and social growth, become aware of their role as adult educators. How would you describe the influence of your life path on your present position/role? How did your previous experience influence your career as an adult educator?

I did not deliberately set out to be an adult educator or researcher and certainly not a university professor. In some ways it happened by accident but in other ways it became a natural fit through life. My formal education began in geology and sciences, and grazed through school education, wildlife and environmental science, philosophy, feminism, educational administration then on to higher, vocational and community education research. While much of what I know has been informed by my formal education, most of what I believe in has been informed by other experiences we rarely acknowledge and talk about. In my case it was about what I learned by 'dropping out' in the 70s, playing in a band, being unemployed several times, walking and riding a bicycle through diverse landscapes, living in rural Australia, coming to terms with place, Indigenous history and landscape, having a family and gardening. I think what I learnt most in this journey is that formal education systems tend to ignore these critically important and less formal ways of learning, knowing and being, including by adults. Formal education, because of the advantages in a meritocracy of wealth, birth, culture, language and place, tends to reinforce a whole raft of existing inequalities. As education systems have become increasingly formal, narrower in their focus towards initial paid work and for profit, the inequities have grown larger and the opportunities for learning beyond them have been ignored and devalued.

Besides the other roles you have, you are a researcher in the field of adult education. Which research fields in adult education should, in your opinion, get more attention? What are the underprivileged groups/areas/fields? What would your argument be for changes in the future?

As a researcher in adult and community education, my interest is in learning in community settings, not in formal educational institutions. Formal education is easier and simpler to 
study because it is a more standard 'product' with more easily defined participants, curriculum, assessment and results -making it particularly amenable for example to scientific, quantitative research. My interest is in the diverse, lifelong and lifewide forms of less formal and informal learning that comprise the much larger but sub-surface part of the 'learning iceberg'.

Older adults enrolled in courses tend to learn about things and are typically relatively well educated. My interest and research passion is in learning occurring at the least formal end of the spectrum for groups who tend to be less formally educated but who often stand to gain most through engaging with other people in learning through communities of practice that is social, local and situated. In essence, my research interest is about the nature and value of open ended learning informally with others in and through the community, not learning individually about something whose content is predetermined. The difficulty as well as benefit of this sort of learning is that it lies beyond the reach and direct influence of governments. The value of research in this field is that it validates and encourages a much wider view of what learning is, who is learning and with what benefits and outcomes, including situated and subjugated learning and so called 'non traditional' learners in diverse community contexts.

While Foucault is not my favourite theorist, I am happy to do as he encourages and 'cherry pick' his apt post-structural term 'subjugated knowledges', that he coined in 1980 to identify what I am most interested in. Also called 'situated knowledges' by some anthropologists and ethnographers by virtue of their typically strong links to cultural and place based-narratives. Foucault suggests, and here I am quoting Tessa Muncey's excellent and incisive 'Creating Autoethnographies' book (p. 44), that subjugated knowledges include:

... all the local regional vernacular, naive knowledges at the bottom of the hierarchy - the low Other of science. These are the non-serious ways of knowing that the dominant culture neglects, excludes, represses, or simply fails to recognise. Subjugated knowledges have been erased because they are ineligible; they exist by and large as active bodies of meaning, outside of books, eluding the forces of inscription that would make them legible, and therefore legitimate ways of knowing.

\section{You are a Patron of Men's Sheds and one of their strongest supporters. How did you become so strongly connected with this movement?}

I was fortunate to be immersed in research into men's informal learning in community settings in rural and remote Australia around the turn of the century (2000) soon after the first Men's Sheds in community settings began appearing from 1998. I became aware from our first serious national study of such Men's Sheds in Australia only a decade ago (in 2007) that the emerging Movement incorporated a very powerful set of social, local and situated community pedagogies that closely matched the interests and needs of 
its mainly older male participants predicted by much of my previous community-based adult education research. Whilst Men's Sheds were not only about learning, there was a lot of powerful and transformative learning occurring through Men's Sheds for an older male demographic almost completely missing from other forms of adult and community education.

Whilst my main role in Men's Sheds has been as a research Professor, I have not hesitated where appropriate as part of what I believe an academic's role is in relation to research impact, to become an informed and passionate advocate, disseminating information and research and assisting new movements to start in other countries, specifically New Zealand, Ireland and across all parts of the EU . My role as Patron of the Australian Men's Shed Association since 2009, whilst voluntary, has given the now international movement and Shed-based organisations a legitimacy with governments, the media and community organisations. I regard Men's Sheds as an excellent example of one of many types of subjugated and situated knowledges that research can make legitimate and visible, in this case benefiting and empowering the Men's Sheds organisations, peak national bodies as well as participants and the Movement. The research also shines a light on the particular needs of older men whom adult educators have often seen as being beyond reach of conventional adult education courses, pedagogies and paradigms by virtue of their age, male gender and relatively low formal education levels.

\section{How and why did men earn and achieve the privilege to have a special community space and community support, in the form of Men's Sheds? Do you believe this is a reason for some women (particularly some feminists) to oppose them?}

This is a very good and important question and it requires me, being located in Australia, to go back in my answer to the 1970s, when women returning to work created the first neighbourhood and community learning centres, that over subsequent decades became a national movement and transformed women's learning, lives and communities. Women and feminists have during the same era identified the need and value for some women to sometimes have some places and spaces where they can meet as women, without men. This value and need is now widely supported and recognised in most but not all countries and cultures.

Population ageing in recent decades has since the 1970s created an increasing proportion of older men beyond paid work, some of whom have not felt comfortable, included, welcome or engaged in some adult and community education providers and some other community programs whose resources, programs, staff and rationale are mainly or solely oriented towards the needs and interests of women. Given the strong and almost universal bias towards women as 'adult learners', as conventionally defined in most nations, there is a case for arguing that some older men are not simply 'absent' from later life learning. Some older men simply do not feel at home or included, and their needs, interests and preferred pedagogies are not necessarily being acknowledged or catered for. 
The first Men's Sheds were created by men and women who understood that some older men sometimes had different interests and needs, for somewhere to go, something to do and someone (mainly men) to talk with. Men's Sheds in community settings powerfully ticked each of these three fundamental needs beyond paid work, and allowed some men with diverse work skills and interests to practice and share their skills: informally, handson, in communities of practice, giving back to their communities, helping each other and improving their wellbeing and happiness.

You will notice I have carefully and consistently been adding the word 'some' in many of my answers - because not all men or all women want or benefit from some gendered programs, services or spaces. The research evidence, however, shows that Men's Sheds are incredibly positive and beneficial for the men who participate, particularly for their happiness, purpose in life beyond paid work and their health and wellbeing - as well as for the community. The experiences of wives and partners of 'shedders', as they call themselves, is typically very positive. If some women, particularly feminists, understand the nature, purpose and ethos of Men's Sheds and still have objections and concerns about them as male gendered spaces, it is important that they be articulated and heard. As with all grassroots community organisations, not every shedder will understand or respect the rights associated with the privilege, responsibilities and benefits of their male gendered space. Again, research confirms that almost all of the men involved are very respectful and caring of other shedders and of the rights of women.

The Men's Shed Movement in most countries has taken a view that whether a particular Men's Shed organisation is just for men or not, the role of women in it is appropriately decided by the local community as well as men and women who are involved in and benefit from its operation. My research shows that the Shed is of most benefit to men if the Shed space is exclusively or mainly for men. The men who benefit most are those with the most acute needs and who are most in need, at that stage of their lives, to spend a day or two a week in the supportive company of other men.

Do you believe that masculinity and the meanings attributed to older men's experience have remained substantially unexpressed and concealed in recent decades? Why have gender perspectives on lifelong and later-life learning been preoccupied with issues relating to women's learning? What is the role of Men's Sheds in relation to feminism and the ability to retain and enhance masculinities?

Women have very effectively self-organised, including through feminism, to create theories, programs and strategies based around what it means to be a woman and to tear down some of the unfair gender barriers in all areas of society, particularly in initial and university education. However many barriers remain for women, including in work, the community and in the home. I believe this work by women to break down barriers should continue and should be supported by men. 
Men have been less successful at articulating, theorising and popularising the positive attributes of masculinity. The various men's movements, including the men's rights organisations, the 'distressed dads', the pro-feminists and the mythopoetic men (who want to recreate male ritual) have very different theoretical starting points and have never achieved traction or popularity in any country beyond their special interests. Being old and male has at times become unfairly linked to presuppose 'dirty old' when men volunteer to become involved in the community in later life. The idea that a grassroots movement could be created for and by older men that models and promotes positive attributes and masculinity in community settings would have been unthinkable in Australia before the Men's Shed movement.

Men now in their 60s and beyond make up most of the shedder demographic in the 2,000 Men's Sheds organisations across the world in ten countries. All this has happened in less than 20 years, to and by men who have experienced significant changes in gender roles and their own masculinities during their lives. Men's Sheds are an opportunity for such men to practice and exhibit the many positive aspects of masculinity: being a responsible, caring and loving older man in the supportive and non-judgmental company of a diverse range of other men, caring for their health and wellbeing and being better husbands, partners, fathers and grandfathers.

You know most of Men's Sheds, their origins and history of development in Australia. What, in your opinion, are the most important goals of Men's Sheds? What makes Sheds so special? Is it "a Cuppa, a Chat or a Smidgin of Sawdust"? Is it the wellbeing and mental health of men? Is it a safe space where men can gather and talk? What do shedders find the most important? Who are, according to these goals, the "blokes" who come to Sheds?

The most important goal of Men's Sheds is essentially the same as when it all started in Tongala, Victoria in the first Shed to open in 1998: it's 'somewhere to go, something to do, and someone to talk with', in the company of other men. While the benefits flow well beyond the men into families and communities, what makes the Men's Sheds so special are the outcomes in terms of older men's identity, confidence, wellbeing, mental health, self esteem, community spirit and pride in their Shed and its achievements. Yes, it's about feeling and being safe in their identity as diverse and different older men practising positive masculinities, but none of this is happens because of theory: it's all about practice. Importantly, the only thing that unites the men is that all men are equal and welcome. While leaders emerge, no one is in charge and everyone is responsible. Since most Men's Sheds are stand alone, grassroots organisations, they are shaped and organised differently to cater for the diverse and very different needs in different places and communities. As a consequence they cater for many different mainly older 'blokes', with diverse existing and latent interests in many, many different ways. All Sheds are deliberately and appropriately different. 


\section{What is the role of learning in Men's Sheds? Do you believe that, when talking about learning, men have different needs from women? Could Men's Sheds be regarded as an informal learning space in the community?}

The men participate freely and voluntarily: they are not patronised or enrolled as students. Nor are they customers, clients or patients of a professional in the Shed. In pedagogical terms they are empowered as co-participants in a shared community of practice. I would argue that the learning pedagogies are so distinct and different I have playfully but with serious intent coined the term 'shedagogy' to roll together all of the diverse strands in my previous answers about how and why it works. While the men informally share and sharpen their existing skills, the emphasis is on what men know and can do, not what they can't do or don't know.

This is why men feel comfortable, social, empowered and 'at home', informally participating, supporting and mentoring each other in their Shed in a way that they could never feel at home in a formal adult education classroom, a 'study circle' or learning on their own online. Learning typically happens informally in the total absence of formal programs, teachers, curriculum or assessment. The only formal aspect is typically the presence of a safe and well-equipped workshop with tools and material. Most importantly, there is a comfortable social place to meet, talk and have a 'cuppa'.

I think that many women do and would benefit from similar organisations based around similar pedagogies and informal communities of women's practice, including through quilting, gardening, computing, art, pottery, knitting and patchwork, and for some women also by hands on work with wood or metal as typically occurs in Men's Sheds.

Are Men's Sheds an Australian peculiarity, noting that they've developed in Australia but have then spread particularly to NZ, Ireland and the UK? What are, in your opinion, the needs and prospects for Men's Sheds to develop in other EU countries?

The long answer to this question is to be found in my 2015 book, 'The Men's Shed Movement: The Company of Men'. My short answer is that for the first ten years to 2007 all community-based Men's Sheds were in Australia. By 2017 around one half of approximately 2,000 Men's Shed-based organisations set up around the world were outside of Australia, mainly in culturally similar, mainly English speaking nations right across Ireland, the UK, New Zealand, with several now open also in the US and Canada but in small numbers also in Kenya, Denmark and Sweden. In some countries like Denmark, it has been necessary and desirable to find a local name other than Men's Shed (in this case in Danish 'Maens M desteder' (literally 'men's meeting place') and adapt aspects of the original model to better fit older men's different cultural norms.

As in Australia, Men's Sheds have greatest community traction for older men not in paid work in smaller rural communities where such men form a significant proportion of the population. In countries where men already meet socially and informally in gendered 
communities of practice the prospects for Men's Sheds spreading are less likely. In the Nordic countries where fishing and hunting clubs remain strong, and in Mediterranean nations where card and game playing in coffee clubs are intact for many older men, the prospects of a workshop replacing or complementing them are less likely. I suggest that there might be more prospect of a Men's Shed type movement, albeit by a different name and with an appropriate cultural translation, spreading in many Asian nations such as Japan and China, where the post-work roles of men are often difficult and ambiguous. The same might be the case in in many Pacific and African nations where gender-based workshops have been a successful and important part of Indigenous cultural practice across hundreds of generations. The greatest prospect might be in Central and Eastern Europe, as well as in many post-conflict nations, where men's health and wellbeing are relatively poor and where men's involvement in adult learning is particularly low or problematic. Some existing adult education providers might experiment by creating places and spaces within them for older men, incorporating similar 'shedagogies' in workshop settings as I identified earlier, to test and demonstrate what might be possible.

\section{There are also Women's Sheds (She-Sheds) springing up in Australia. What is their role compared to Men's Sheds?}

As I stressed earlier, some women enjoy and benefit from learning in workshop-based settings and other female gendered communities of practice. Some women have expressed an interest in (and been admitted to) Men's Sheds as regular members. In other Sheds there is a day when women are involved or else where women have negotiated a 'women's only' day in the same Shed. Some shed-based organisations choose to be called 'Community Sheds' to equally encourage men and women, but again it is mainly men who choose to participate. There also is a very small number of 'Women's Sheds', some calling themselves 'She-Sheds' in Australia, Ireland and the UK. I should also note that some relatively recent workshop-based 'Makerspaces' and Dutch Repair Cafés have been set up in which are not gendered and which successfully tend to attract a younger demographic. Their participants typically want shared access to tools and technologies in a shared workshop to make and fix their own things in the community. This is a movement for researchers to watch out for closely in the future.

\section{Thank you very much for your answers, Barry, and all the best for your future work and life challenges!}

